\title{
Kidney Lesions in Rats with Severe Long-term Alloxan Diabetes
}

\section{Influence of Age, Alloxan Damage, and Insulin Administration}

\author{
By \\ H. Ørskov, T. Steen Olsen, K. Nielsen, O.J. Rafaelsen and K. Lundbaek \\ From the University Institute of Pathology (Head: Professor STEEN OusEN) and the 2nd University Clinic of \\ Internal Medicine (Head: Professor Knod Londbek), Kommunehospitalet, Aarhus, Denmark \\ Received July 8, 1965
}

\begin{abstract}
Summary. Alloxan diabetes was induced in rats by intraperitoneal injection or by injection into the vena cava. In 3 groups the renal vessels were clamped during, and for some minutes after, the injection. The histological appearance of the kidneys after 5,10 and 15 months of diabetes was compared with findings in groups of untreated rats of the same age as well as in non-diabetic rats treated with insulin throughout comparable periods. The glomeruli of the alloxan diabetic rats showed changes similar but not quite identical to the human diabetic glomerulopathy. These changes were present only after diabetes of 10 months. The main difference is that the rats showed no actual nodules and that the PAS-positive hyalinosis of the arterioles, characteristic of human longterm diabetes, was absent. The glomerular changes are not age-conditioned, and the results do not suggest that the administration of insulin or direct alloxan damage played any role in inducing these lesions. Tubular damage (atrophy, dilatation) and interstitial fibrosis were most marked in rats which had not been protected against the high initial alloxan concentration in the blood by clamping the renal vessels.
\end{abstract}

Résumé. Des groupes de rats furent rendus diabétiques par une injection intrapéritonéale d'alloxane ou par une injection dans la veine cave inférieure. Dans quelques-uns des groupes les vaisseaux rénaux furent pincés pendant et durant quelques minutes après l'injection. La structure histologique du rein après 5,10 et 15 mois de diabète fut comparée avec celle de rats non-injectés du même âge, et aussi avec celle de rats non-diabétiques traités avec de l'insuline pendant toute la de l'expérience. Dans les corpuscules de Malpighi des rats diabétiques nous avons trouvé des modifications pathologiques très semblables, bien que pas tout à fait identiques, à la glomérulopathie diabétique chez l'homme. Ces modifications ne se montrent qu'après 10 mois de diabète. La principale différence entre la pathologie des rats alloxanisés et celle des diabétiques humains est l'absence de nodules sphériques ainsi que de l'hyalinose PAS-positive des artérioles chez le rat. Les altérations glomérulaires ne dépendaient pas de l'âge des rats. Elles n'étaient causées ni par le traitement à l'insuline, ni par une lésion directe due à l'alloxane. Les altérations tubulaires (atrophie, dilatations) et la fibrose interstitielle étaient plus prononcées chez les rats qui n'avaient pas été protégés par pincement des vaisseaux rénaux contre le taux sanguin d'alloxane initialement très élevé.

Zusammenfassung: Durch Injektion von Alloxan (intraperitoneal oder in die Vena cava) wurde bei Ratten ein Diabetes erzeugt. Bei 3 Gruppen wurden die Nierengefäße während und einige Minuten nach der Injektion abgeklemmt. Die histologische Struktur der Niere, die nach einer Diabetes-Dauer von 5, 10 und 15 Monaten zu beobachten war, wurde mit den Ergebnissen verglichen, die sich bei unbehandelten und bei chronisch mit Insulin behandelten Tieren fanden. In den Glomerula der Alloxan-diabetischen Ratten fanden sich Veränderungen, die ähnlich, aber nicht ganz identisch mit der diabetischen. Glomerulopathie des Menschen ist. Diese Veränderungen ergaben sich nur nach einer Dauer des Diabetes von 10 Monaten. Der wichtigste Unterschied zwischen den renalen Veränderungen der Alloxan-diabetischen Ratten. und denen des Menschen mit langdauerndem Diabetes ist die Abwesenheit der eigentlichen Knoten in den Glomerula und der PAS-positiven Hyalinose der Arteriolen. Die beobachteten Veränderungen der Glomerula sind nicht altersbedingt. Sie sind nicht auf die Insulingabe und nicht auf eine Alloxanschädigung zu beziehen. Die Tubulusveränderungen (Atrophie und Dilatation) und die interstitielle Fibrose waren besonders deutlich bei den Ratten, die gegen die hohe initiale Alloxankonzentration im Blut nicht durch Abklemmen der Nierengefäße geschützt gewesen waren.
The structure of the kidney in rats with experimental alloxan diabetes has been studied by CuRTIs, RoBBINs and Glickmann ${ }^{6}$, Beveridge and Johnson ${ }^{5}$, MANN, Goddard and ADAMS ${ }^{12}$, JANES ${ }^{11}$, and GreENBERG $^{9}$. Foglia, Mancini and Cardeza ${ }^{8}$ have studied the kidneys of pancreatectomized diabetic rats. BEASer, SAK and Sommers ${ }^{3}$ and Beaser, Sak, DonaldSon, McLadghtin and Sommers ${ }^{4}$ have described the renal changes in alloxan-diabetic hamsters (Mesocricetus auratus). Some of these authors have found glomerular and tubular as well as interstitial lesions of the renal tissue after diabetes of varying duration.

The object of the present study was to ascertain whether direct alloxan damage contributes to the ap- pearance of the kidney lesions and whether long-term insulin administration per se can induce renal changes. Studies on the histochemical nature and ultrastructure of the changes will be published elsewhere (STEEN OLsen et al. ${ }^{16}$, Østerby Hansen et al. ${ }^{14}$.

\section{Methods}

The experiments were carried out during the period 1961 to 1964 on Wistar female rats of an initial weight of $100-150 \mathrm{~g}$. The animals were about $2^{1} / 2$ months old at the start of the experiment.

The experimental conditions are listed in Table 1.

It will be seen that the duration of diabetes was 15 months (group 00), 10-11 months (group 02 and 03) and 5 months (group 09 and 10) respectively. 
Table 1. Experimental conditions and chemical findings

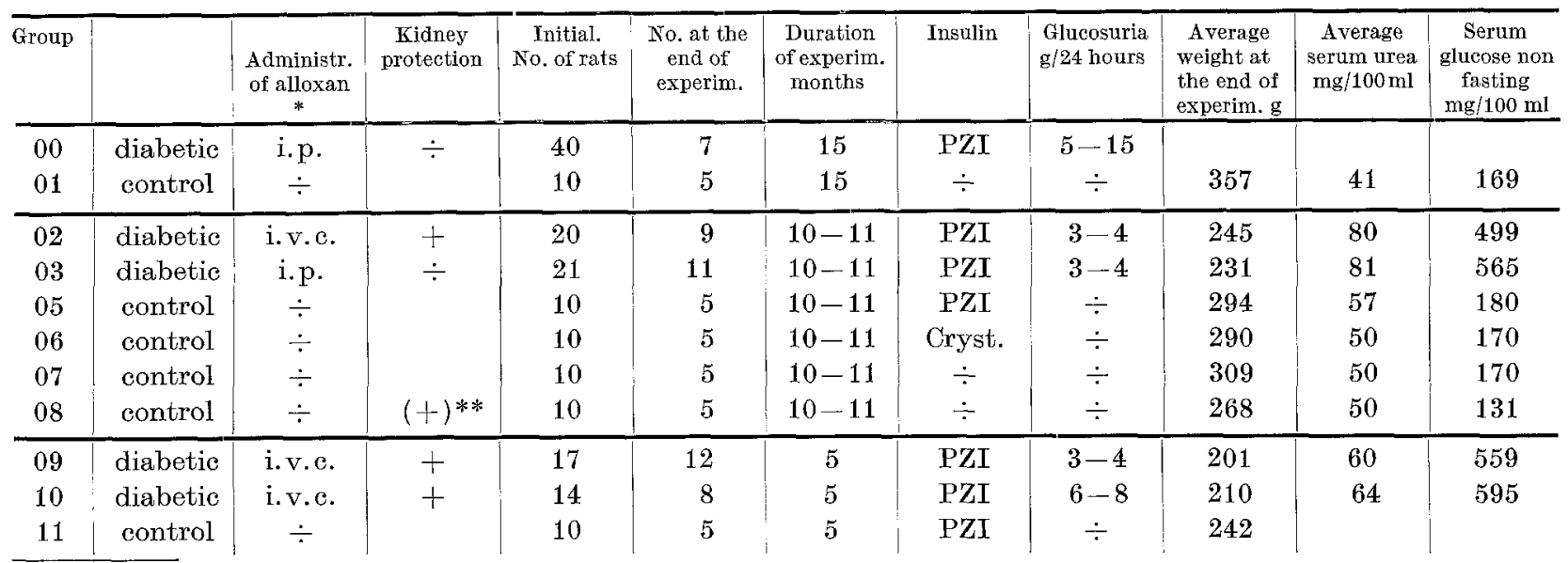

* i.p.: intraperitoneal injection, i.v.c.: injection into the vena cava. ** Clamping without alloxan injection.

The rats of group 00 had very severe alloxan diabetes, but in this first group no attempt was made to maintain a fixed degree of diabetes. The rats of groups 02,03 , and 09 had fixed moderate diabetes while the rats of group 10 had fixed severe diabetes. These two degrees of diabetes were defined by 24 hour urine outputs at $30-40 \mathrm{ml}$ and $60-80 \mathrm{ml}$ respectively. As the urinary concentration of glucose in such rats is invariably about $10 \%$, this corresponds to a sugar excretion of $3-4$ and $6-8 \mathrm{~g} / 24$ hours respectively. The adjustment was made by giving every day the suitable dose of insulin, assessed on the basis of an unchanged, increasing, or decreasing output of urine during the preceding 24 hours. By means of this individual adjustment of insulin dose it was possible to obtain degrees of diabetes which remained extremely constant for the many months of the experiment (ØRskov $\left.{ }^{13}\right)$.

The alloxan (alloxan monohydrate, Hofmann-La Roche, later on Light) was administered intraperitoneally in doses of $200 \mathrm{mg} / \mathrm{kg}$ or into the vena cava in doses of $70 \mathrm{mg} / \mathrm{kg}$. Other experiments were performed with "kidney protection", i.e. the renal vessels being clamped off during the injection of alloxan and for 5 minutes thereafter. With this technique the post-operative mortality was practically nil, and $90 \%$ of the rats developed insulin-requiring diabetes with a tendency to acidosis. This method also gives a normal histological appearance of the kidney on light microscopy and normal values of laboratory renal investigations on the days following the administration of alloxan (SøGAARD, ØRSKOV and ØSTERBY ${ }^{15}$ ).

During the experimental period the diabetic and the control rats were kept in single cages with a constant temperature and humidity and with facilities for collecting urine. They were given water and a vitamin feed. mixture ad libitum (carbohydrate $65 \%$, protein $30 \%$, fat $5 \%$ ).

The rats were inspected morning and evening. Every morning the urinary output was measured. On this basis the dosage of insulin was determined, as stated above. The preparation used was protamine zinc insulin $(5 \mathrm{IU} / \mathrm{ml})$ administered subcutaneously. The rats were weighed at 2 weekly intervals. The urine was tested daily for ketones and monthly for protein.

Insulin shock was rare among these rats with a high constant glycosuria. On the other hand, the majority had one or more episodes of ketoacidosis with marked polypnoea, dehydration, and ketonuria. Rats believed to have no chance of survival were killed. Otherwise classical coma treatment was given.
Rats were included in the series that had died less than 6 hours previously and that did not show severe autolytic changes on being dissected. Only 5 rats of this category were included.

When rats or groups of rats had attained the desired duration of diabetes, samples of midstream urine were collected for investigation of sediment and quantitative urinary protein. The abdomen was opened under anaesthesia, and the right kidney removed immediately after the application of a clamp. Tissue from this kidney was fixed in osmic acid for electron microscopy. The remainder of the kidney was fixed in Lilly's fluid. Thereafter, a cannula was introduced into the aorta and a few $\mathrm{ml}$ of blood removed for chemical investigation. The left kidney was perfused through the renal artery with physiological saline and subsequently with Carnoy's solution.

After dehydration in alcohol the specimens were embedded in parafin in the conventional manner and cut into sections of approx. $4-5 \mu$. The sections were stained with haematoxylin-eosin, van Gieson-Hansen, PAShaematoxylin, trichrome-Masson, and periodic acid-silvermethenamine, counter-stained with haematoxylin-eosin.

\section{Definitions}

\section{Results}

Glomerula: Various grades of glomerular changes were found and evaluated semi-quantitatively as described below (ef. also Fig. 1-5).

Severe changes $(+++)$ : The changes were visible with all stainings, but most distinct in the PAS-stained preparations. They consisted of widespread thickening of the capillary walls in the glomerula. These deposits were strongly PAS-positive and affected large parts of the glomerulum, but seldom its entirety. The changes were homogeneous, but in a few places there was a slightly fibrillar or reticular structure. Pale vacuoles of varying size were found in some of the deposits. Often there was occlusion of the entire capillary. In the PAS-positive deposits small, round, pale cells (endothelial) were occasionally observed, situated in a lacuna without any relation to a vascular lumen. 


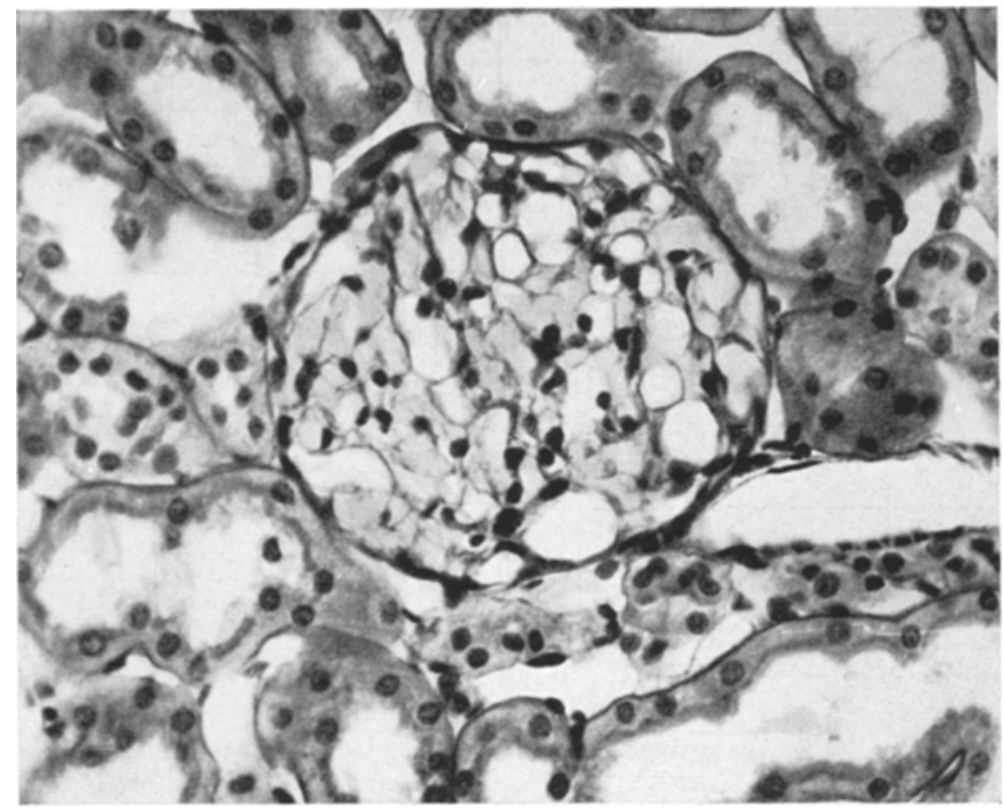

Fig. 1. Normal glomerulum from control group 15. Fixation by perfusion with Carnoy's fluid. PAS-hematoxylin staining

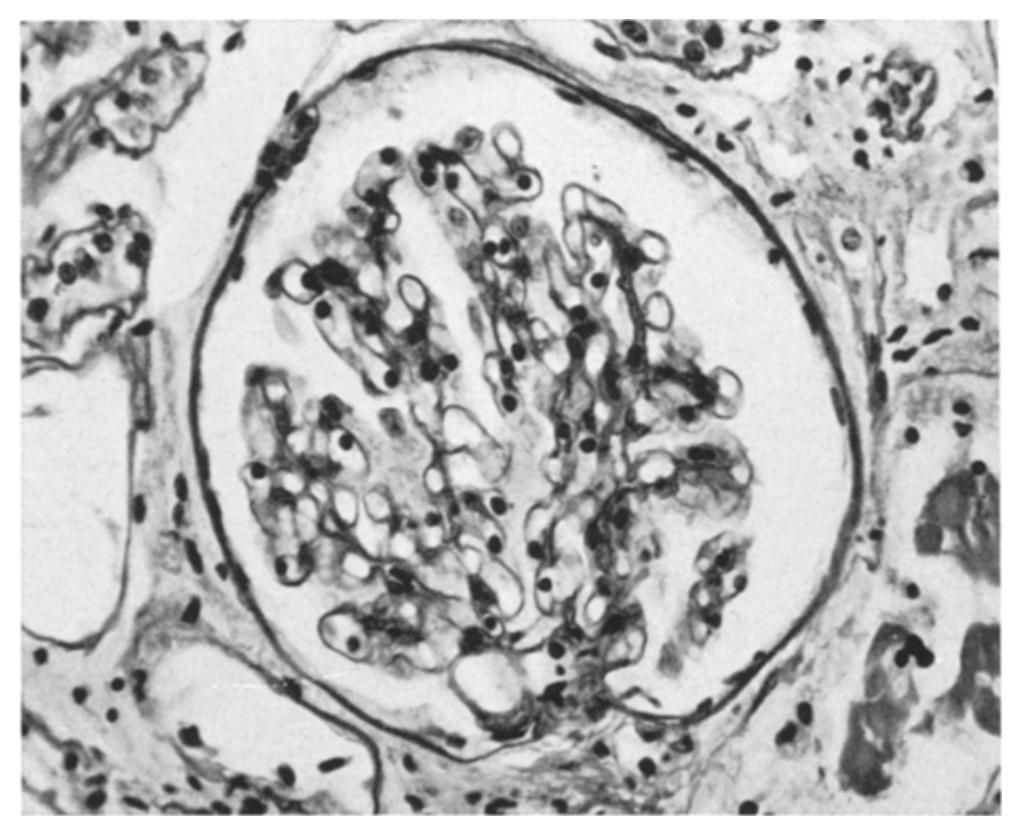

Fig. 2. Glomerulum from a case with grade + damage. Very slight diffuse thickening of capillary wall. Fixation and staining as Fig. 1
These changes bore some similarity to the corresponding changes ("fibrinoid caps") in human glomerulosclerosis. The deposits often merge peripherally with Bowman's capsule, forming wide synechiae. The Bowman's capsule often showed moderate, homogeneous thickening. The deposited material consisted of a glycoprotein, and in the most severe cases there were also deposits of lipid in the individual glomeruli. The "severe changes" were often present only in one-third to two-thirds of the entire glomerulum. Not all the glomeruli were affected, but the changes were seen in $10-70 \%$ of all glomerula in each individual case.

Moderate changes $(++)$ : These glomerular changes were of fundamentally the same nature as those described above, only a little less marked and involving fewer glomerula. The lumina of the glomerular capillaries were seldom completely occluded. All the capillary walls were the seat of diffuse PAS-positive mural thickening.

Mild changes $(+)$ : These changes were mild, but unmistakable when compared with the glomerula of normal rats. They can best be described as a diffuse, fairly uniform, PAS-positive thickening of the glomerular walls and mesangial regions. Cases estimated as +++ or ++ often showed + changes in some of the glomeruli or in parts of individual glomerula. This diffuse thickening of the vascular walls, as seen on light microscopy, was very similar to the diffuse changes in human diabetes.

The grading of the renal damage in each individual rat was based upon the frequency of the various glomerular lesions as well as upon their severity, each case showing glomerula of widely different appearance.

Arterioles: Some rats showed thickening of the arteriolar walls due to medial hyperplasia and concentric fibrosis of the adventitia. Hyaline, homogeneous, PAS-positive thickening of the arteriolar wall of the type seen in human diabetics was not observed in the present material.
The deposits were present peripherally as well as axially in the individual lobules and in the central stalk. They did not assume the shape of nodules with surrounding nuclei as seen in the human KimmelstielWilson lesion; they might rather be described as sausage-like. The deposition most often appears to take place on the endothelial side of the basement membrane. In a few glomerula, however, there were welldefined caps, evidently situated on the epithelial side.
Table 2. Glomerular changes in relation to duration of diabetes

\begin{tabular}{l|c|r|r|r|c}
\hline \multirow{2}{*}{$\begin{array}{l}\text { Grades of } \\
\text { severity }\end{array}$} & Controls & \multicolumn{3}{|c|}{ Diabetie rats } & Total \\
& & 5 mo. & 10 mo. & 15 mo. & \\
\hline+++ & 0 & 0 & 0 & 5 & 5 \\
++ & 0 & 0 & 3 & 2 & 5 \\
+ & 1 & 0 & 12 & 0 & 13 \\
0 & 35 & 22 & 5 & 0 & 62 \\
\hline total & $\mathbf{3 6}$ & 22 & 20 & 7 &
\end{tabular}


Tubules and interstitial tissue: A number of rats showed tubular dilatation with epithelial flattening, protein-containing, moderately PAS-positive casts, and moderate interstitial fibrosis and lymphocytic infiltration. The renal tubules contained at times degenerated, foamy, desquamated epithelial cells, more rarely leukocytes. The epithelium lining normally dimensioned as well as dilated tubules, mainly the proximal ones, was in some cases the seat of severe fatty degeneration, demonstrated by Fett-rot, Sudan III, and Sudan Black on frozen sections. The tubular and interstitial changes were classified semi-quantitatively into 3 grades :,+++++ , and + .

\section{Findings}

The results are shown in Tables $2-5$.

From Table 2 it may be seen that severe glomerular changes were found in 5 out of the 7 rats in the 15 -months group. Moderate changes were seen in the 2 other rats of this group as well as in 3 of the 20 rats in the 10-months group. Mild changes were found in 12 of the 10 -months rats. No rat with diabetes of only 5 months duration had glomerular changes on light microscopy, while one out of 36 controls had changes corresponding to the definition "mild changes".

Table 3 shows that a certain correlation is present between the grade of changes in the glomeruli and in the tubules.

It appears from Table 4 that glomerular changes were equally common in rats with and without kidney protection. It is apparent from Table 5 that those with renal protection were less apt to show signs of tubular and interstitial damage than those without.

Diabetic rats with severe glomerular changes showed faintly PAS-positive thickening of the arteriolar walls, caused by medial hyperplasia and concentric adventitial fibrosis.

The majority of diabetic rats with diabetes of 15 and 10 months duration had more or less marked tubular and interstitial

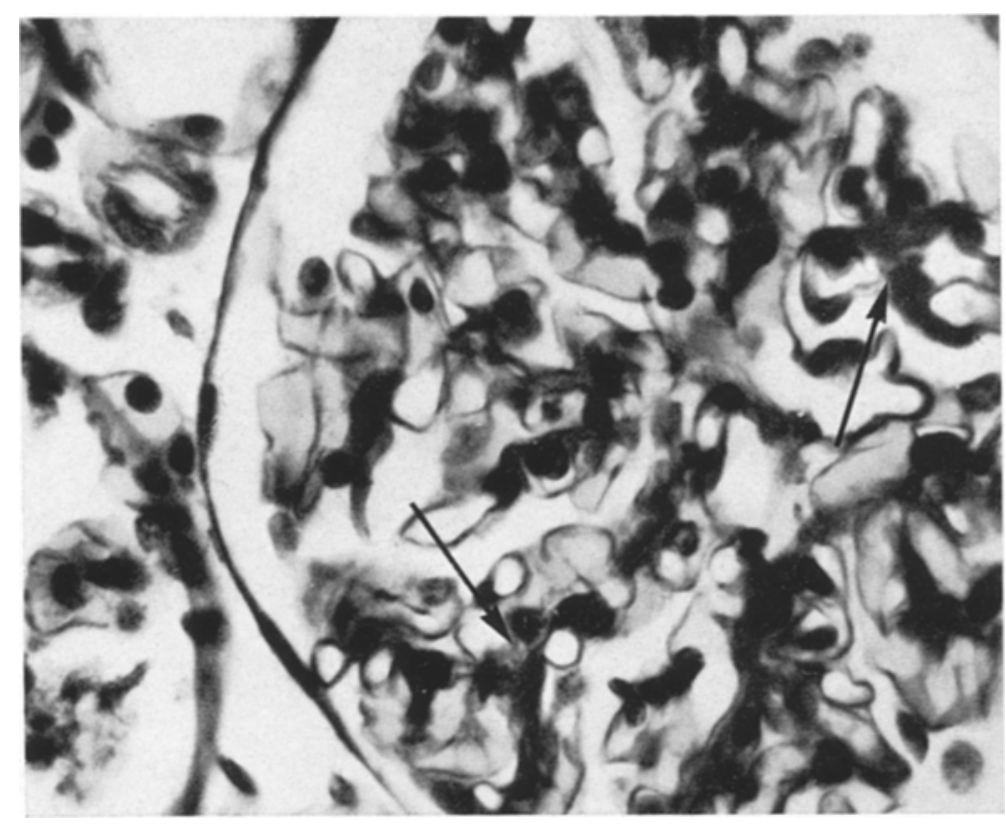

Fig. 3. Glomerulum from a case graded ++ , The diffuse thickening is slightly more advanced than in Fig. 2, especially in mesangial regions (arrows). Same fixation and staining as Fig. 1

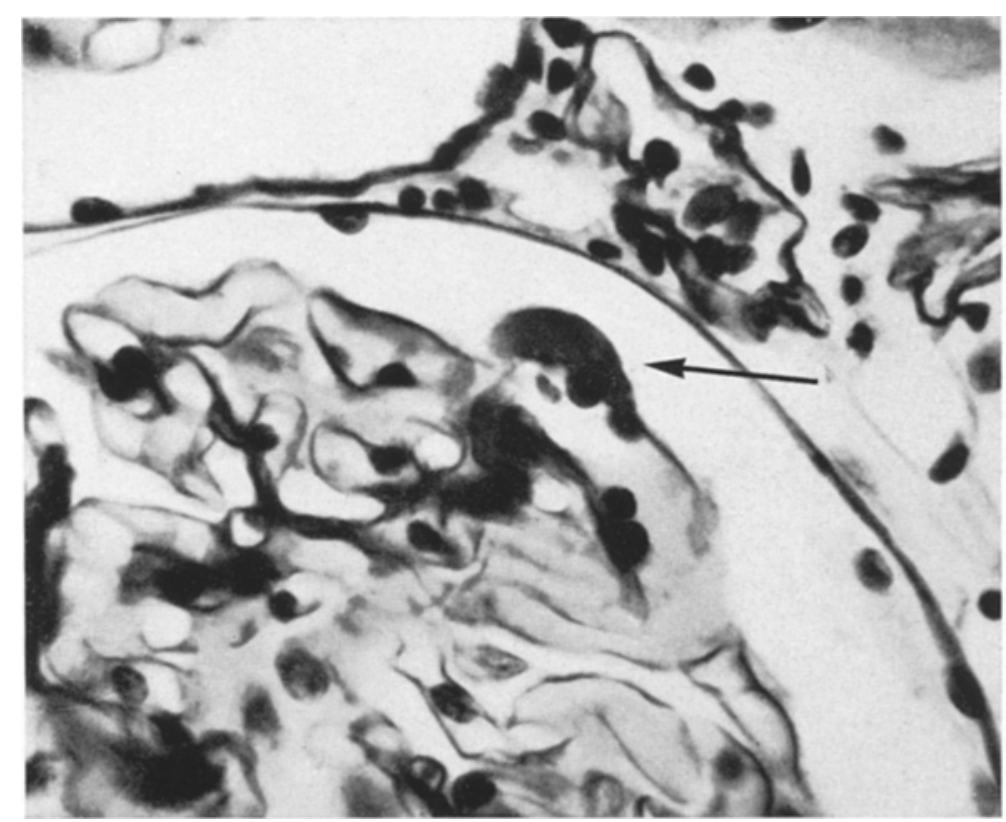

Fig. 4. Same case as Fig. 3. Arrow at a deposit at the epithelial side of basement membrane. Fixation and staining as Fig. 1
Table 3. Correlation between glomerular and tubulo/interstitial renal lesions

\begin{tabular}{l|c|c|c|c}
\hline tub./int. & +++ & ++ & + & 0 \\
\hline Glom. & 2 & 2 & 1 & 0 \\
+++ & 0 & 4 & 1 & 1 \\
++ & 0 & 1 & 5 & 6 \\
+ & 0 & 1 & 2 & 60 \\
0 & & & &
\end{tabular}

\begin{tabular}{c|c|c}
\hline Severity & Kidney protected & Not protected \\
\hline+++ & 0 & 0 \\
++ & 2 & 2 \\
+ & 5 & 6 \\
0 & 1 & 3
\end{tabular}

Table 4. Glomerular lesions in rats with 10 months duration with and without kidney protection 


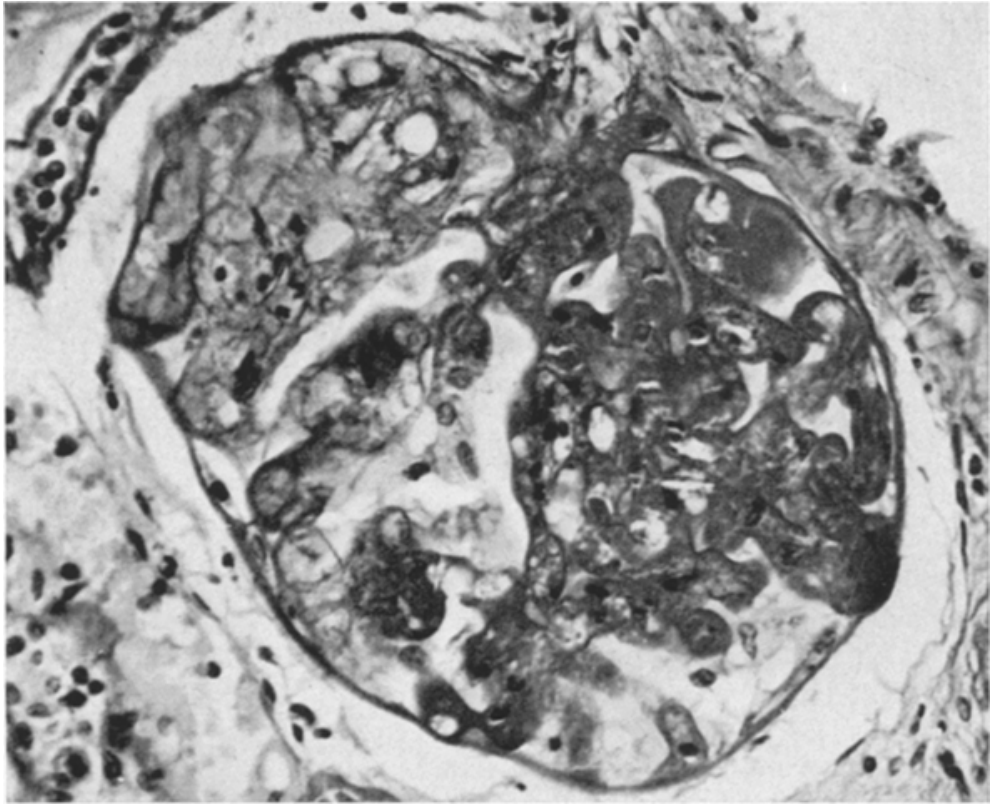

Fig. 5. Glomerulum from a case with grade +++ damage. This is the maximal degree of glomerular lesion observed. Deposits are presumably at the endothelial side, often filling the capillary lumen. Formalin fixation, staining as Fig. 1

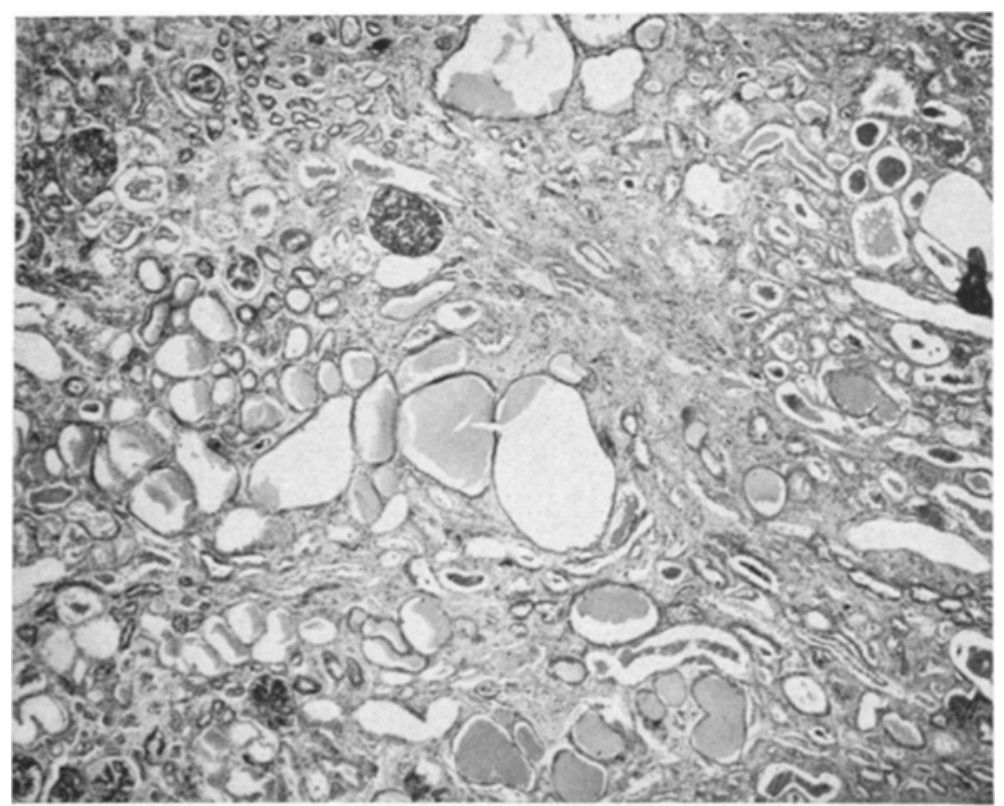

Fig. 6. Kidney with interstitial fibrosis, tubular dilatation and casts, classified as grade +++ tubular/interstitial damage. Fixation and staining as Fig. 5

Table 5. Tubular and interstitial changes in rats with 10 months duration with and without kidney protection

\begin{tabular}{c|c|c}
\hline & \multicolumn{2}{|c}{ Kidney protection } \\
\hline Severity & with & without \\
+++ & 0 & 0 \\
++ & 2 & 4 \\
+ & 1 & 6 \\
0 & 6 & 1
\end{tabular}

changes. Lipid degeneration was observed in all the rats of the 15-months group and in some of those of the 10-months group. Rats that died with high blood glucose levels showed distinct hydropic degeneration and the presence of glycogen in the epithelium of the tubules, especially in the distal ones and in Henle's loops (ArmanniEbstein lesion).

The controls did not exhibit changes of the arterioles, tubules, or interstitial tissue.

\section{Insulin}

In the control groups of non-diabetic rats that received insulin treatment (protamine zinc insulin in groups 05 and 11 , regular insulin in group 06) renal appearances were entirely normal.

Age

The histological structure of the kidney was normal and identical in the control groups of animals of various ages. In 5 older rats ( 26 months) mild senile changes were observed.

\section{Severity of Diabetes}

Only the rats of the 5-months group were adjusted to two different levels of severity of diabetes. As none of these rats exhibited glomerular changes, the experiment gives no information regarding the significance of the severity of the diabetes. The rats of the 15-months group had the most severe degree of diabetes, but it was not accurately adjusted to different levels of control.

\section{Clamping of Renal Vessels}

In the control experiments, where the operations consisted merely of clamping the renal vessels for 5 minutes (group 08), there were no histological changes in the kidneys.

\section{Urinary and Blood Changes}

There was a rough correlation between the histological changes and the serum urea. Most of the rats, including the controls, had slight proteinuria (positive Albustix). Only a few rats showed urinary casts.

\section{Discussion}

In the present experiments it was possible to demonstrate that in rats with an alloxan-induced metabolic abnormality of diabetes (insulin-deficiency diabetes), 
severe changes may be produced in the renal glomerula. These changes bear certain resemblances to human diabetic nephropathy, mainly with respect to a deposition of a PAS-positive substance in the capillary walls with far-reaching histochemical similarities with human glomerular lesions (STEEN Olser et al. ${ }^{16}$ ). The results obtained show that the experimental lesion has a pre-stage resembling the diffuse human type. There is no complete morphological identity between the advanced human lesions and the experimental, diabetic, glomerular ones. The shape of the deposits in the rat is sausage-like, owing to filling of the capillary coils, while in man the characteristic finding is spherical intercapillary PAS-positive deposits. Another difference is that human glomerulopathy is almost invariably accompanied by a distinct PAS-positive, hyaline thickening of the arteriolar walls which was not observed in the rat.

In our experiments the diabetic glomerulopathy in the rat could be demonstrated only after 10 months diabetes. The most severe changes were found after 15 months of diabetes. However, the difference between these two groups lies not merely in the duration, but also in the severity of the diabetes.

It might be asked whether the glomerular changes were caused by the acute action of alloxan, the acutely damaged glomerula subsequently having a tendency to change in the direction described. However, it has been demonstrated that the glomerula are normal a short time after the injection of alloxan (Østerby Hansen, SøgaARD and $\emptyset_{\text {RSKov }}{ }^{15}$. In our material the most severe glomerular changes were found in a group of rats with diabetes of $\mathbf{1 5}$ months duration. This group does not include kidneyprotected rats, but a comparison of the 10 -months rats with and without protection showed that moderate and mild glomerular changes were equally common. Accordingly, it is unlikely that the action of alloxan upon the kidney has been a factor in the development of the glomerular lesions.

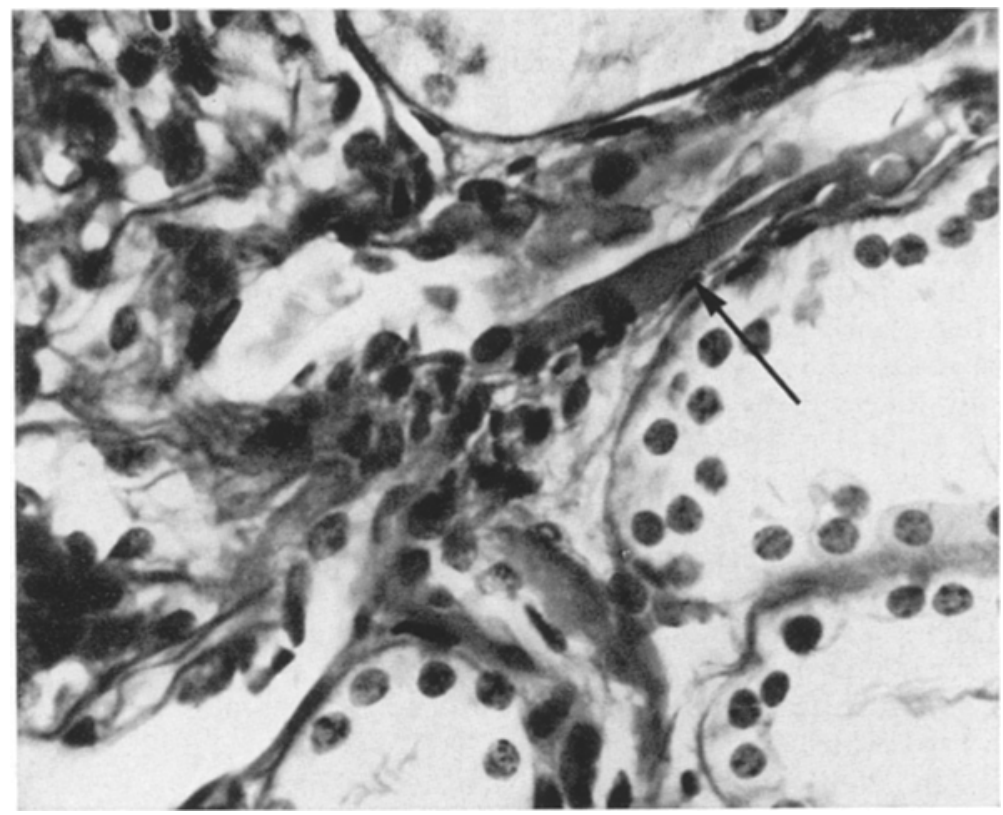

Fig. 7. Vascular pole from glomerulum. Human case of long term diabetes. Glomerular lesion was of severe nodular type (not illustrated). Arrow at hyaline, PAS-positive thickening of arteriolar wall. Formalin fixation, staining with PAS-hematoxylin

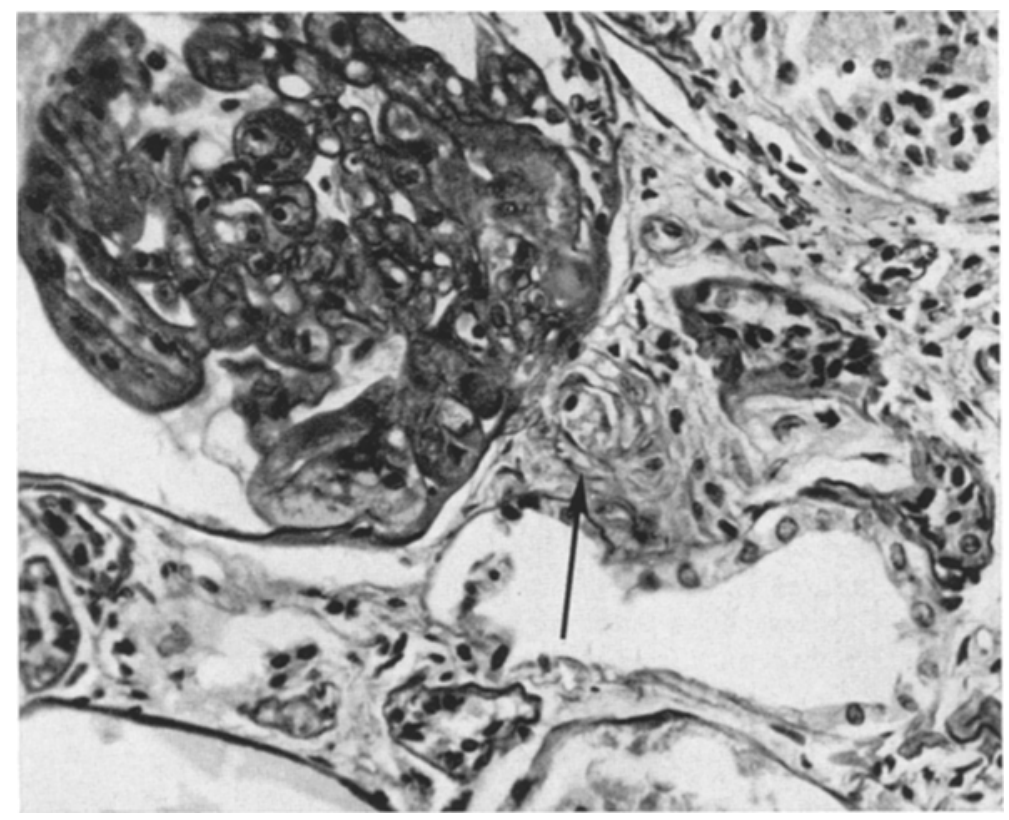

Fig. 8. Vaseular pole from rat with severe $(+t+)$ glomerular damage. Arrow at tangentially cut arteriole without deposits in the wall (compare with Fig. 7). Fixation and staining as Fig. 7

The glomerular changes are not due to age-conditioned glomerular sclerosis. In parallel groups of rats of the same age, but without diabetes, we found completely normal renal tissue without glomerular changes. As a supplement, we studied a group of 5 nondiabetic rats that were 26 months old. The kidneys from these rats occasionally showed mild lobular fibrosis of the glomerulum. However, these appearances

were clearly distinguishable from diabetic glomerular lesions, and, as mentioned already, they were never observed in the age groups used for our experiments. We can, therefore, definitely rule out any confusion with age-conditioned glomerular sclerosis.

GRIEBLE ${ }^{10}$ has described glomerular lesions induced by injection of insulin into non-diabetic rabbits. The changes did not resemble ours. The completely nega- 
tive result of the experiments in control groups $0,5,06$, and 11 shows that in our experiments there is no question of insulin-induced damage to the glomeruli.

The result of the experiments does not permit definite conclusions with respect to the influence of the severity of the diabetes. In this connection, it should be borne in mind that the fact that the 15-month old rats had the most severe and most commonly occurring glomerular changes, does not necessarily show that this difference is due exclusively to the increased duration of diabetes.

MANN et al. ${ }^{12}$ and $J_{A N E S}{ }^{11}$ have reported the observation of glomerular changes after a short duration of diabetes, but their description of the experimental conditions is so sparse that it is difficult to assess the significance of their findings. The same applies to GreenBera's ${ }^{9}$ studies. Incidentally, his mild glomerular changes do not appear convincing in the illustration, whereas his severe changes resemble those observed by us.

In addition to the glomerulopathy we found in our experimental material tubular and interstitial changes, manifesting themselves as tubular atrophy, tubular dilatation, degeneration of the tubular epithelium, and as the presence of easts which were PASpositive and contained protein. Moreover, moderate interstitial fibrosis and lymphocytic infiltration was observed in some cases. On the other hand, accumulations of polymorphonuclear leukocytes were uncommon.

These tubular and interstitial changes bear a certain resemblance to those which may be observed in human diabetic nephropathy. However, the tubular dilatation and the occurrence of casts is more striking in the rats, while human diabetic nephropathy, in its advanced stages, is more typically accompanied by diffuse interstitial fibrosis and tubular atrophy.

In our experiments it must be considered whether the tubular and interstitial changes may be due, wholly or partially, to direct alloxan damage. It is well-known that alloxan causes severe acute tubular degeneration during the first days after injection (DUNN et al. ${ }^{7}$.) ARTETA ${ }^{1,2}$ has performed experiments on dogs in which he clamped one renal pedicle while alloxan was being injected into the contralateral renal artery. 6-8 weeks later he found severe sclerotic changes with atrophic, dilated tubules, casts, and interstitial fibrosis on the side of the injection. These dogs did not develop diabetes. Thus, it is beyond doubt that the acute, tubular degeneration may later result in interstitial and tubular changes as seen in our rats.

Our two 10-month groups were identical in respect to severity of diabetes, but one was kidney-protected in the way described above. The tubular and interstitial lesions were more pronounced in the unprotected group. This might suggest that at least a major factor in these lesions is the toxic influence of alloxan. The fact that the changes were not present in our 5-month group does not invalidate this hypothesis, as all our 5-month rats were kidney-protected.

In our experiments there is a certain correlation between the grade of glomerular and tubular changes, which might suggest a pathogenetic correlation between these changes. It must be mentioned, however, that 8 of the 10 rats with +++ or ++ tubulointerstitial changes had not received kidney protection.

All considered, therefore, it seems that direct alloxan damage is the most important cause of the tubular changes in our experiments. However, they may also occur in kidney-protected rats and - provided that this protection has been adequate - they cannot then be ascribed to alloxan alone.

It is possible that the diabetic state per se leads to tubulo-interstitial changes in the kidneys, but it is also highly conceivable that these lesions are simply secondary to the glomerular changes. It must be expected that the renal parenchyma (the tubules) become the seat of local ischaemia in areas supplied with blood from the perishing glomerula, with consequent local tubular atrophy, fibrosis, and round-cell infiltration. Some, but not all, glomeruli are totally occluded in advanced experimental glomerulopathy, so that the flow of blood through these glomerula must be greatly compromised or completely arrested.

In alloxan-diabetic hamsters BEASER, SAK and Sommers ${ }^{4}$ (1963) found tubular and interstitial changes which were very reminiscent of those found by us in rats with severe alloxan diabetes. They call these changes "pyelonephritis", but there is no definite evidence that the changes were caused by chronic bacterial infection of the renal parenchyma. The same applies to the nature of the interstitial and tubular changes seen in human diabetic glomerulosclerosis.

\section{Acknowledgements}

This study was aided by the Danish Science Foundation, the F.L. Smith Jubilee Foundation, the Novo Foundation, and the Foundation for the Advancement of Medical Science.

We wish to express our gratitude to Mr. Anton Rasmussen and Mr. Erik V. Andersen for skilful technical assistance.

\section{References}

1 ArTeta, J.L.: Mechanism of protection action of clamping renal pedicles of dogs with alloxan diabetes. J. Endocrinol. 8, 245-249 (1952).

2 - Kidney and alloxan, researches on their role in the production of alloxan diabetes. Acta Physiol. Latinam. 2, 65-72 (1952).

3 Beaser, S. B., M.F. SAK and S.C. Sommers: Influence of insulin therapy and pyelonephritis upon diabetic glomerulosclerosis in hamsters. Metabolism. 12, $704-709$ (1963).

4 - - G.W. Donatioson, R.J. Mo Laughuin and S.C. Sommers: Alloxan diabetes in the golden hamster, Mesocricetus auratus. Diabetes 13, $49-53$ (1964).

${ }^{5}$ Beveridae, J.M.R., and S.E. Johnson: Studies on diabetic rats: Production of cardiovascular and renal disease in diabetic rats. Brit. J. Exper. Path. 31, $285-293(1950)$. 
${ }^{6}$ Curtis, G. W., S.L. Robbins and I. Glickman: Studies on glycogen nephrosis in alloxan-treated diabetic rats. J. Exper. Med. 85, 373-379 (1947).

7 DunN, J.S., and N.G.B. MoLetchie: Experimental alloxan diabetes in rat. Lancet. 1943 II, $384-387$.

${ }^{8}$ Fogtia, V.G., R.E. Mancint and A.F. Cardeza: Glomerular lesions in the diabetic rat. A.M.A. Arch. Path. 50, 75-83 (1950).

${ }^{9}$ Greenterg, S.R.: Glomerular changes in chronic alloxan diabetes. A.M.A. Arch. Path. 73, 263-273 (1962).

${ }^{10}$ GrIEBLE, H.G.: Renal lesions induced by heterogeneous insulin. J. Lab. clin. Med. 56, 819-820 (1960).

11 JANES, R.G.: The relationship between eye and kidney pathology in the diabetic rat. A.M.A. Arch. Path. 67, $386-394$ (1959).

12 Mann, G.V., J.W. Goddard and L. Adams: The renal lesions associated with experimental diabetes in the rat. Amer. J. Path. 27, 857 (1951).
13 ØRSkov, H.: Light dependent seasonal variation of insulin sensitivity in the alloxan diabetic rat. To be published (1966).

14 Osterby Hansen, R., T. Steen Olisen, K. Lundark and H. ØRskov: Kidney lesions in rats with severe long-term diabetes, III : Electronmicroscopic studies. To be published (1966).

15 - H. SøgaARD and H. Ørskov: The effect of renal clamping on acute alloxan lesions. To be published (1966).

16 STEEN OLSEN, T., H. ØRskov and K. Lundb atK : Kidney lesions in rats with severe long-term diabetes, II: Histochemical studies. Acta path. et microbiol. 66, $1-12(1966)$.

Dr. H. Ørskov

2nd University Clinic of Internal Medicine Kommunehospitalet Aarhus/Denmark 